\title{
sciendo
}

\section{Ketogenic Diet and Skeletal Muscle Hypertrophy: a Frenemy Relationship?}

\author{
by \\ Antonio Paoli ${ }^{1,2}$, Pasqualina Cancellara ${ }^{1}$, Pierluigi Pompei ${ }^{3}$, Tatiana Moro ${ }^{4,5}$
}

Ketogenic diet (KD) is a nutritional regimen characterized by a high-fat and an adequate protein content and a very low carbohydrate level (less than $20 \mathrm{~g}$ per day or 5\% of total daily energy intake). The insufficient level of carbohydrates forces the body to primarily use fat instead of sugar as a fuel source. Due to its characteristic, KD has often been used to treat metabolic disorders, obesity, cardiovascular disease, and type 2 diabetes. Skeletal muscle constitutes $40 \%$ of total body mass and is one of the major sites of glucose disposal. $K D$ is a well-defined approach to induce weight loss, with its role in muscle adaptation and muscle hypertrophy less understood. Considering this lack of knowledge, the aim of this review was to examine the scientific evidence about the effects of KD on muscle hypertrophy. We first described the mechanisms of muscle hypertrophy per se, and secondly, we discussed the characteristics and the metabolic function of KD. Ultimately, we provided the potential mechanism that could explain the influence of KD on skeletal muscle hypertrophy.

Key words: ketogenic diet, skeletal muscle hypertrophy, resistance training, signaling, muscle protein synthesis.

\section{Introduction}

Interactions between nutrition and skeletal muscle hypertrophy have been widely investigated. Several studies have analysed the effects of different macronutrients (Escobar et al., 2016; Phillips, 2017; Witard et al., 2016) and the energy intake amount (Hector et al., 2018) on muscle mass variations. Indeed, the size of skeletal muscle is the result of the balance between muscle protein synthesis (MPS) and muscle protein breakdown (MPB). The algebraic sum of MPS and MPB results in the net protein balance (NPB). Only with a positive NPB it is possible to achieve muscle protein accretion and, consequently, growth of muscle fiber size (Stokes et al., 2018). Many factors influence NPB (Figure 1 ), and among the others, nutrition together with resistance training play a pivotal role (Witard et al., 2016). Amino acids (AA) and protein ingestion lead to an increase (though transient) in the MPS' rate (Morton et al., 2015). The importance of protein quality and quantity in MPS has been widely investigated throughout the last 20 years (Mitchell et al., 2016; Phillips, 2011; Tipton and Phillips, 2013; van Loon and Gibala, 2011). Nowadays, it is well established that a minimal level of protein intake is mandatory to stimulate significant muscle growth (Churchward-Venne et al., 2016; Paddon-Jones et al., 2008; Phillips, 2012, 2017; Reidy and Rasmussen, 2016). However, this minimal level is still upon debate and relates also to body size and typology of training (Macnaughton et al., 2016; Moore et al., 2009)

Considering the paramount importance of protein intake as a skeletal muscle protein

1 - Department of Biomedical Sciences, University of Padua, Padua, Italy.

2 - Research Center for High Performance Sport, UCAM, Catholic University of Murcia, Murcia 30107, Spain.

3 - Unit of Pharmacology, School of Pharmacy, University of Camerino, Italy.

4 - Sealy Center on Aging, University of Texas Medical Branch, Galveston, TX.

5 - Department of Nutrition \& Metabolism, University of Texas Medical Branch, Galveston, TX. 
synthesis stimulus, it is somewhat surprising that a relatively high protein diet such as the very low carbohydrate ketogenic diet, more simply called ketogenic diet (KD) (Paoli, 2018), has been, till now, poorly investigated as far as its effects on skeletal muscle hypertrophy are concerned. KD is a nutritional approach consisting of high-fat and an adequate protein content, but of an insufficient level of carbohydrates for metabolic needs (less than $20 \mathrm{~g}$ per day or $5 \%$ of total daily energy intake; Paoli et al., 2015a), thus forcing the body to primarily use fat as a fuel source. Given this lack of knowledge, our aim was to review all scientific evidence about the effects of $\mathrm{KD}$ on muscle hypertrophy, dissecting the mechanisms of muscle hypertrophy per se, then discussing the characteristics and the metabolic effects of KD and finally, hypothesizing the potential influence of KD on muscle hypertrophy.

\section{Skeletal Muscle Hypertrophy}

Skeletal muscle tissue plays a pivotal role in the regulation of whole body metabolism, functional work capacity and exercise performance (Egan and Zierath, 2013). Muscle plasticity is an essential feature that makes this tissue able to react to different stimuli. Muscle hypertrophy is, for example, the accretion of muscle fiber size that may occur in response to resistance exercise. Understanding the molecular mechanisms of this muscle adaptation is important to counteract the opposite mechanism such as muscle atrophy that is related to many pathological conditions (disuse, cancer, denervation injury, aging) (Glass, 2003).

As previously stated, muscle mass ensures dynamic equilibrium between muscle loss/catabolism (MPB) and muscle growth/anabolism (MPS) (Figure 1). Indeed, balance between the rates of synthesis and degradation of muscle protein or net protein balance yields changes in the amount of muscle myofibrillar proteins therefore, influencing muscle mass. Exercise and nutrition are two interventions that influence rates of MPS and MPB and, ultimately, the NPB. It is well known that nutrition influences, per se, both MPS and MPB.

Measuring muscle protein synthesis (MPS) and muscle protein breakdown (MPB)

Protein Turnover

Physiological and metabolic homeostasis is strictly influenced by the regulation of MPS and MPB. Indeed, $80 \%$ of the daily protein synthesis comes from the recycling of amino acids from MBP, while only $20 \%$ seem to be induced by protein intake with diet (Wolfe and Chinkes, 2005). Under the post-absorptive condition, MPB is approximately $30 \%$ higher compared to MPS (Biolo et al., 1994), thus the nitrogen balance is, at basal fasting condition, normally negative. Anabolic stimuli, such as consumption of AA or exercise, can increase MPS by improving the efficacy of recycling EAA from MPB (Wolfe, 2017). Thus, understanding the mechanism of both protein synthesis and breakdown is a fundamental step to assess adequate strategy of intervention to regulate muscle protein turnover. MPS

Muscle protein synthesis could be defined as the process in which new proteins are produced. MPS is directly activated via the mammalian/mechanistic target of rapamycin complex 1 (mTORC1) system (Dickinson et al., 2011; Drummond et al., 2009), containing the regulatory protein mTOR (Saxton and Sabatini, 2017). When appropriately stimulated by an increased concentration of AA, insulin or subsequent to mechanical stress induced by muscle contraction, mTORC1 complex translocates into the lysosome where it can interact with the G-protein Ras homolog enriched in the brain (Rheb) (Bar-Peled and Sabatini, 2012). The translation initiation and elongation process are then triggered: S6K1(Thr389) phosphorylation activates eIF4B (Holz et al., 2005; Saxton and Sabatini, 2017) which regulates the translation initiation and the kinase eEF2k (Wang et al., 2006) to promote the translation elongation process; simultaneously, the eukaryotic initiation factor 4E-binding protein 1 (4E-BP1) is inhibited by mTORC1 by its phosphorylation (at Thr37/46), allowing the dissociation of eIF4F and mRNA translation (Thoreen et al., 2012).

MPB

Muscle protein breakdown is an important metabolic process that results in protein degradation. MPB function is to enable protein and amino acids availability that could be used during stress, such as nutrient depravation or exercise. MPB is regulated by three different protein-dependent systems that can work independently or synergistically: autophagy, the 
ubiquitin-proteasomal pathway (UPP) and the calpain $\mathrm{Ca}^{2+}$-dependent cysteine proteases.

Autophagy is a lysosomal degradation system sensitive to energy accessibility, particularly efficient to disrupt bound proteins, intracellular organelles and damaged proteins (Masiero et al., 2009). Autophagy uses the autophagosome to surround and sequester the lysosome, where the targeted protein complex is degraded.

The UPP system is the primary ATPdependent mechanism of protein degradation and targets short-lived proteins. The UPP regulation of protein breakdown depends on the $26 \mathrm{kDa}$ proteasome, which attracts those proteins conjugated with ubiquitin molecules via an E3 ubiquitin ligase, such as the ubiquitin ligases muscle RING finger protein 1 (MuRF1) and Atrogin 1 (Bodine and Baehr, 2014; Murton et al., 2008).

Sarcolemmal, cytoskeletal and myofibrillar proteins are finally degraded by the calpain $\mathrm{Ca}^{2+}$-dependent cysteine proteases. This process requires specific levels of $\mathrm{Ca}^{2+}$ to activate the enzyme that leads to proteolysis (Dargelos et al., 2008). Therefore, it seems that the calpain system is activated during muscle injuries, when cytosolic $\mathrm{Ca}^{2+}$ levels rises (Goll et al., 1992).

Methods for assessing muscle protein metabolism

Dynamic assessment of MPS and MPB can be determined using stable isotope methodologies (Wolfe and Chinkes, 2005). Stable isotopes are non-radioactive molecules, naturally enriched with heavier atoms, which results in a different molecular mass, but functionally identical to the endogenous counterparts. Thanks to the mass spectrometry technique, it is then possible to measure the incorporation of the isotopic labelled molecules (usually, not metabolized essential amino acids such as phenylaniline) into blood or muscle tissue, thus measuring the rate of muscle protein turnover. The two most common methods used to asses MPS and MPS are the two-pool (or AV balance, arterial and venous poll) and the three-pool (arterial, venous and muscle) model. In both methodologies it is assumed that a physiological and isotopic steady state is achieved by a constant infusion of the tracer.

Then, the differences between arterial and venous enrichment of the labeled tracer are calculated, and the amount of the tracer disappearing from the arterial blood is assumed to represent MPS, while the amount of the tracer released in the vein represents MPB or the outward flux of amino acids from the muscle to the venous pool (Biolo et al., 1994; Wolfe and Chinkes, 2005). However, the arteriovenous blood balance does not consider the portion of the amino acids that is recycled in the intracellular pool and the rate of their transportation. For this reason, the three-pool model is probably a better method to asses muscle protein turnover as it includes the isotopic enrichment of the intracellular amino acids obtained by a muscle biopsy (Biolo et al., 1995).

Despite the important and unique information that can be obtained by tracer methodology, its limitations including the invasivity of the technique, the numerous assumptions that are not always possible to be supported (such as a physiological steady state) and the remarkable cost of the material (Pacy et al., 1989; Thompson et al., 1989; Wolfe and Chinkes, 2005) have to be taken into consideration.

MPS and MPB can also be measured via changes in molecular signals of specific muscle proteins. Measuring RNA via the quantitative real-time polymerase chain (qRT-PCR) or the most recent RNA-sequencing (RNA-seq) technique, protein levels or western blotting, provides indices of the protein signaling pathway at individual time points. The most common proteins studied as markers of MPS are linked to the $\mathrm{mTOR}$ and the insulin signaling pathway. mTORC1 downstream that targets $\mathrm{S} 6$ kinase 1 (S6K1) and 4E-binding protein 1 (4E-BP1), together with the stimulation of the insulinsignaling pathway through phosphatydilinositol 3-kinase (PI3K) and phosphorylated protein kinase $\mathrm{B}(\mathrm{Akt} / \mathrm{PKB})$, has been widely investigated in nutrition and exercise studies (Avruch et al., 2006; Bodine et al., 2001; Dickinson et al., 2011; Drummond et al., 2009). On the other hand, expression of MuRF1 and atrogin 1 as well as other E3-ubiquitin ligases are the molecular pathway for MPB (Fry et al., 2013; Pasiakos and Carbone, 2014).

The major limitation of these static methodologies for measuring muscle protein turnover is related to their time sensitivity. Those 
are, in fact, a sort of a "snap-shot" of what is happening in the muscle, and each protein has its own time course. Moreover, an increase in the mRNA expression not always translates in an increase in protein production (Atherton et al., 2016).

\section{Molecular machineries involved in skeletal muscle hypertrophy}

Protein balance is, at a deeper level, controlled by a complex molecular apparatus that has either a negative or a positive muscle growth effect. There are three main pathways involved in the skeletal muscle mass control, mitochondrial biogenesis and metabolic homeostasis signalling pathways (Sandri et al., 2013): 1) IGF$1 / \mathrm{Akt} / \mathrm{mTOR}$, 2) FOXO/MuRF1, and 3) AMPK/PGC1 $\alpha$ pathways. While the IGF1/Akt/mTOR and the FOXO/MuRF1 pathways are involved in the first control mechanisms, the latter functions are under the control of the AMPK/PGC1 $\alpha$ pathway.

As described above, skeletal muscle protein synthesis following exercise is mainly regulated by mTORC1 that is part of the IGF-AktmTOR signalling pathway (Schiaffino and Mammucari, 2011; Wackerhage et al., 2019). Specifically, IGF-1 binds to its receptor that in turn phosphorylases the insulin receptor substrate (IRS) which activates phosphatidylinositol-3kinase (PI3K). PI3K phosphorylates membrane phospholipids, leading to formation of phosphoinositide-3,4,5-triphosphate (PIP3) that acts as a docking site for two kinases, phosphoinositide dependent kinase 1 (PDK1) and Akt. PDK1 activates Akt which on one hand inhibits protein degradation by repressing the members of the Forkhead box class $\mathrm{O}$ family member proteins (FoxO), and on the other stimulates protein synthesis via mTOR and glycogen synthase kinase 3b (GSK3b). mTOR forms two protein complexes, the rapamycin sensitive mTORC1 with Raptor, and rapamycin insensitive mTORC2 with Rictor (Zoncu et al., 2011). mTORC2 phosphorylates Akt at serine 473 for its maximum activation, while mTORC1 phosphorylates the S6K1 that activates the ribosomal protein S6 and other proteins to stimulate protein synthesis (Schiaffino and Mammucari, 2011).

One of the crucial actions of Akt is also the inhibition of FoxO. Skeletal muscle presents three transcriptional factors of the FoxO family: Foxo1, Foxo3 and Foxo4. All these three factors can be inhibited by Akt, through phosphorylation (Brunet et al., 1999; Sandri et al., 2013). FoxOs control numerous genes related to muscle atrophy. In particular, under stress conditions such as fasting or disuse, FoxOs promote the expression of Murf1 and Atrogin-1 genes, and consequently rule out their protein abundance (Bodine and Baehr, 2014). As described above, these two ligases are linked to the UPP system and regulate protein breakdown.

On the other hand, 5'-adenosine monophosphate-activated protein kinase (AMPK) is a key regulator of muscle homeostasis (Merrill et al., 1997; Winder and Thomson, 2007). AMPK is an intracellular sensor of ATP, activated when the intramuscular AMP:ATP ratio increases, to promote fuel utilization.

Due to its function, AMPK inhibits muscle growth and has a negative impact on those processes that consume ATP, such as protein synthesis (Romanello et al., 2010; Weerasekara et al., 2014). The inhibitory action of AMPK on muscle protein synthesis mainly occurs through the inhibition of mTORC1: AMPK can directly phosphorylate mTOR in one or both of its two sites (Thr2446 and Ser2448) (Cheng et al., 2004; Figueiredo et al., 2017); or indirectly by the phosphorylation of the tuberous sclerosis complex 2 (TSC2) (Long et al., 2005); or phosphorylating RAPTOR, a regulatory-associated protein required for mTORC1 activity (Gwinn et al., 2008). Moreover, AMPK can exercise its inhibitory action blocking the downstream binding of the elongation factor eEF2 to the ribosome. This process can occur via mTOR inhibition or directly, phosphorylating eEF2k, an eEF2 kinase, that has a negative control on the elongation process (Horman et al., 2002; Rose and Richter, 2009). Thus, AMPK could be considered a negative regulator of muscle hypertrophy, as its phosphorylation is correlated with a reduction in muscle protein synthesis (Dreyer et al., 2006; Gordon et al., 2008; Thomson and Gordon, 2005; Thomson et al., 2008). In addition, it seems that AMPK activation could promote the shift from the glycolytic to the more oxidative fiber status, via the peroxisome proliferator-activated receptor gamma coactivator-1 alpha (PGC-1a), which promotes mitochondrial biogenesis (Garcia and 
Shaw, 2017; Mounier et al., 2015).

\section{Ketogenic Diet}

KD is a high fat and moderately high protein diet in which the level of carbohydrate must be below $30 \mathrm{~g} /$ day or $5 \%$ of total energy intake (Paoli et al., 2015a). During KD an important shift at the metabolic level occurs. The lack or the reduction of dietary carbohydrates decreases plasma insulin and increases glucagon; this state promotes hepatic glycogenolysis and gluconeogenesis as well as lipolysis of adipose tissue through the increase of HSL (hormone sensitive lipase). Thus, after a period of $\mathrm{CHO}$ restriction (in general 4-7 days), glycogenolysis becomes not sufficient anymore and the increased levels of free fatty-acids and of acetyl CoA (through mitochondrial beta-oxidation), lead to ketogenesis. The end-products of this process are the ketone bodies: acetoacetate (AcAc), betahydroxybutyrate (BHB) and acetone (McPherson and McEneny, 2012; Paoli, 2014). The production of ketone bodies is stimulated by the overproduction of acetyl-CoA (increased lipolysis and beta-oxidation) without concomitant production of an adequate amount of oxaloacetic acid (Paoli et al., 2015a). It is thus worthy to underline that the reduction of glucose flux, due to the nutritional carbohydrate restriction, leads to a lower level of oxaloacetate. Oxaloacetate is an intermediate of the TCA (tricarbossilic acid cyle, or Kreb's cycle) and it is unstable at average body's temperature. Thus, it is necessary to re-fuel an adequate amount of oxaloacetate through the (almost) only feasible way in mammalian: the conversion of piruvate into oxaloacetate. The imbalance between the two fluxes: production of FFA and production of oxaloacetate, leads to an excess of FFAs that are converted in the liver into the three KBs (Paoli et al., 2013). This process is called ketogenesis and principally occurs in the mitochondrial matrix of the liver (Veech, 2004). When glycogen's stores are depleted, glycaemia is maintained stable mainly through the so-called gluconeogenesis process. In humans, gluconeogenesis usually derivates from the concession of a carbonic skeleton from those few amino acids with gluconeogenetic properties (ie. Alanine, Glutamine, Glycine). In overweight and obese people also glycerol derived from triglycerides provides an important source of glucose (Bortz et al., 1972). These two sources maintain a stable glycaemia index and avoid hypoglycaemia during fasting or a ketogenic diet. Ketone bodies are then captured by extrahepatic tissues from circulation and used as an energy source. Anyway, $10-20 \%$ of KBs could be lost in the urine. KBs are used as an alternative source of energy through a pathway that firstly converts $3 \mathrm{HB}$ back to AcAc which is then transformed into acetoacetyl-CoA. The latter is finally divided into two molecules of acetyl-CoA, which are subsequently used in the Krebs cycle. Furthermore, compared with glucose, the energy produced from KBs is greater (Fukao et al., 2004; Paoli et al., 2014). During KD, the low amount of carbohydrate intake stabilizes glycaemia at a physiological range around 3.61-4.44 $\mathrm{mmol} / \mathrm{L}$ (65$80 \mathrm{mg} / \mathrm{dL}$ ), while the level of ketone bodies (KBs) reaches a maximum level of 3-4 mmol/L (usually $1.2-2 \mathrm{mmol} / \mathrm{L}$ ) with low insulin levels (Paoli et al., 2013). This situation is known as "Ketosis" (increase in ketone bodies) which also occurs physiologically after prolonged fasting and exercise.

In the physiological context blood $\mathrm{pH}$ does not change; conversely in uncontrolled diabetic ketoacidosis, ketonemia can exceed $20 \mathrm{mmol} / \mathrm{l}$ with concomitant lowering of blood $\mathrm{pH}$, that can lead to potentially lethal ketoacidosis. To differentiate this pathological condition from ketosis induced by fasting or KD, already in 1966, Hans Krebs called the latest condition "physiological ketosis" (Krebs, 1966).

If properly managed, the "physiological ketosis" is not dangerous and can be a useful tool to treat different pathological conditions. Historically, the VLCKD has been used to treat epilepsy, in particular in children who were nonresponders to pharmacological interventions (Rho, 2017). More recently, the therapeutic use of this diet type in other diseases such as metabolic disorders, obesity, cardiovascular disease, type 2 diabetes and also some types of cancer, has raised great interest. In the last 10-15 years there has been a dramatic increase in the number of published research on ketogenic diet and different diseases. Indeed in 2013, we published a review suggesting some strong emerging evidence about the role of KD in different diseases (Paoli et al., 2013) which has been mostly confirmed so far. Many articles have been published indicating positive effects of $\mathrm{KD}$ on neurological diseases 
such as Alzheimer's diseases (Ota et al., 2019; Taylor et al., 2018), ALS (Ari et al., 2014), brain trauma (concussion) (Zhang et al., 2018), migraine (Di Lorenzo et al., 2018), PCOS (Mavropoulos et al., 2005), and cancer (Klement, 2019). Moreover, new scenarios are opening such as the effects of
BHB on epigenetics changes (Newman and Verdin, 2013; Ruan and Crawford, 2018), inflammation (Paoli et al., 2015b) and microbiota (Olson et al., 2018).

Table 1

Characteristics of studies performed on $K D$ and resistance training. $R T=$ resistance training

\begin{tabular}{|c|c|c|c|c|c|}
\hline Study & $\begin{array}{l}\text { Effects } \\
\text { on } \\
\text { LBM }\end{array}$ & $\begin{array}{c}\mathrm{RT} \\
(\mathrm{Yes} / \mathrm{No})\end{array}$ & $\begin{array}{l}\text { Athletes } \\
\text { (Yes/No) }\end{array}$ & $\begin{array}{l}\text { Protein } \mathrm{g} / \mathrm{kgbw} / \text { day } \\
\text { reported }\end{array}$ & $\begin{array}{l}\text { Protein } \mathrm{g} / \mathrm{kgbw} / \text { day } \\
\text { calculated }\end{array}$ \\
\hline $\begin{array}{l}\text { Wilson et al. } \\
\text { (2017) }\end{array}$ & $\uparrow$ & Yes & Yes & No & 1.73 \\
\hline $\begin{array}{l}\text { Vargas et al. } \\
\quad(2018)\end{array}$ & $=$ & Yes & Yes & 2.0 & / \\
\hline $\begin{array}{l}\text { Kephart et al } \\
\text { (2018) }\end{array}$ & $=$ & Yes & Yes & No & $\sim 1.0$ \\
\hline $\begin{array}{c}\text { Greene et al. } \\
\text { (2018) }\end{array}$ & $\downarrow$ & Yes & Yes & No & $\sim 1.6$ \\
\hline $\begin{array}{l}\text { Paoli et al. } \\
\text { (2012) }\end{array}$ & $=$ & Yes & Yes & 2.2 & I \\
\hline $\begin{array}{l}\text { Wood et al. } \\
\text { (2012) }\end{array}$ & $\downarrow$ & Yes & No & No & $\sim 1.18$ \\
\hline $\begin{array}{c}\text { Jabekk et al. } \\
(2010)\end{array}$ & $=$ & Yes & No & No & $\sim 1.0$ \\
\hline
\end{tabular}
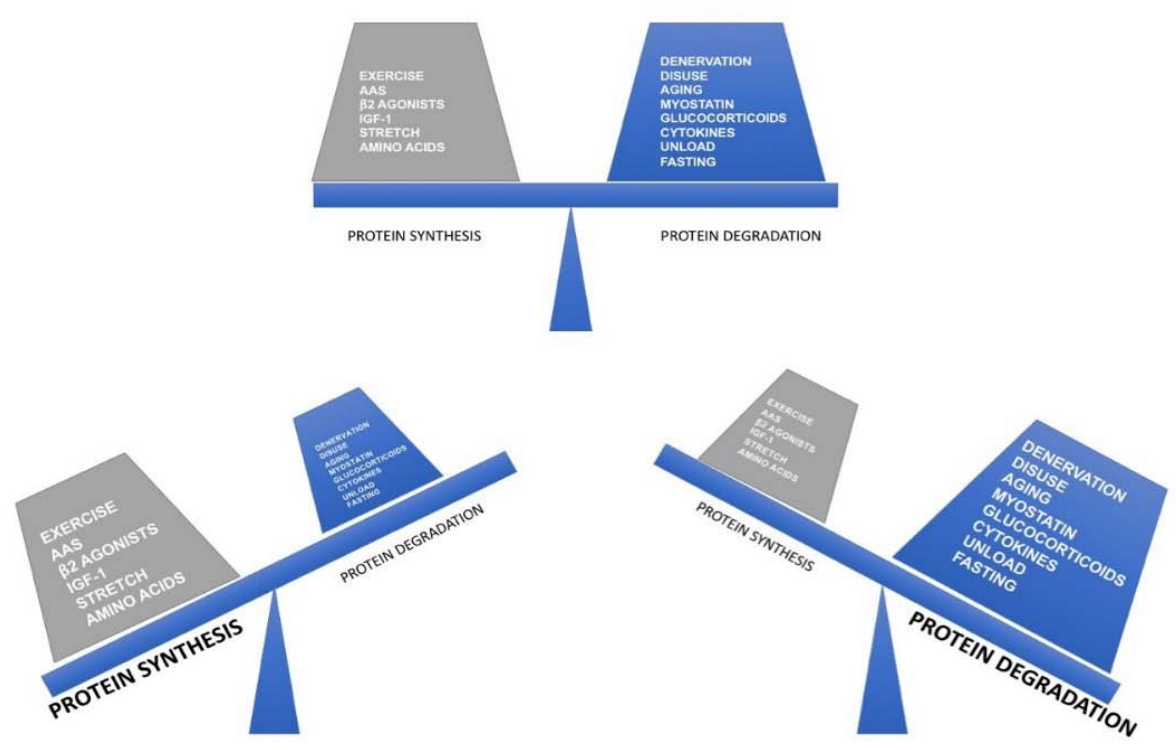

Figure 1

Factors that influence skeletal muscle protein balance ( $A A S=$ Androgen Anabolic

Steroids). An increase in positive protein balance's factors stimulates protein synthesis, on the opposite an increase in negative protein balance's factors stimulates protein degradation. The sum of these two parts of the scale defines the net protein balance (NPB). 


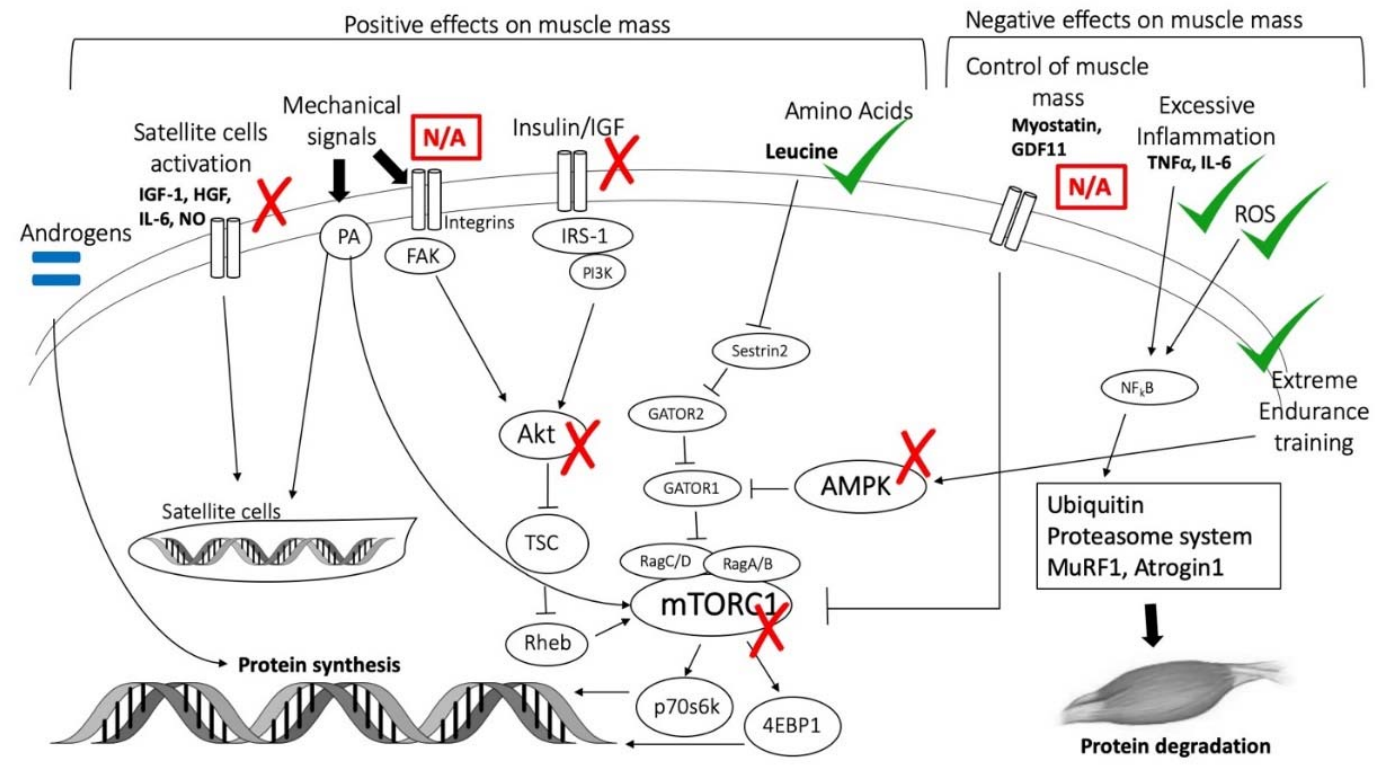

Figure 2

Effects of KD on muscle mass control pathways. IGF-1 = insulin-like growth factor-1;

HGF = Hepatocyte growth factor; IL-6=Interleukin-6; NO = Nitric Oxide; $P A=$ phosphatidic acid; FAK = Focal adhesion kinase; IRS-1 = Insulin receptor substrate-1; PI3K = Phosphoinositide 3-kinase; $A K T=$ protein kinase $B ; T S C=$ Tuberous sclerosis protein; Gap activity toward Rags 1; GATOR2, Gap activity toward Rags 2; AMPK= $5^{\prime}$ adenosine monophosphate- activated protein kinase; Rheb $=$ Ras homolog enriched in brain; $m$ TORC1 = mammalian/mechanistic target of rapamycin complex $1 ; p 70 s 6 k=S 6$ kinase beta-1; 4EBP1 = 4E-binding protein 1; GDF11 = Growth differentiation factor 11; TNF $\alpha=$ Tumor necrosis factor $\alpha$; ROS = Reactive oxygen species; $\mathrm{NF}_{\mathrm{k}} \mathrm{B}=$ nuclear factor kappa-light-chain-enhancer of activated B cells; MuRF1 = Muscle RING-finger protein-1.

\section{Ketogenic diet and muscle mass}

There are conflicting data about the effect of chronic very low carbohydrate (ketogenic) diet on lean body mass, muscle mass and exercise. Wilson and collaborators (2017) recently showed an increase in muscle mass after 10 weeks of KD and 2 weeks of carbohydrate reintroduction in resistance trained males, while Vargas et al. (2018), Paoli et al. (2012), Kephart et al. (2018), and Jabekk et al. (2010) found a general conservation of muscle mass with no significant increases.

In another study, authors showed a similar decrease in lean body mass during $\mathrm{KD}$ with resistance training, KD without training and low fat diet with resistance training, while the loss of muscle mass was greater after a low fat diet without resistance training suggesting a protective effect of KD on muscle mass compared to a low fat diet in absence of training (Wood et al., 2012). Moreover, a recent paper investigating the effects of $\mathrm{KD}$ on body composition and performance in weight lifters found a decrease in lean body mass without negative effects on specific sport's performance (Greene et al., 2018). 
One confounding factor might be the amount of daily protein intake expressed as grams of protein per kilogram of body mass (Table 1) and the fitness level of subjects (sedentary, overweight or active/athletes).

\section{Effects of ketogenic diet on skeletal muscle protein balance}

Muscle protein balance is clearly influenced, directly or indirectly, by many nutritional factors. We can summarize, according to different authors (Hoppeler et al., 2011) these factors into positive regulators such as growth factors, AA signalling, hormones, mechanical stimuli, and negative regulators such as Myostatin, GDF11, chronic low-grade inflammation and continuous repeated contractions.

\section{Hormones}

It is well known that some hormones exert anabolic effects on skeletal muscle; among others, the most powerful are testosterone, growth hormone (and its downstream: IGF-1) and insulin. Data available on mice showed that KD per se did not influence testosterone levels, while testosterone was reduced by a caloric restriction regimen and, instead, increased by a high fat diet (Kennedy et al., 2007). In humans, less data are available: Volek and colleagues (2001) found no effects on testosterone levels of a high fat-low carbohydrate diet. On the contrary, recently, an increase in testosterone levels has been shown after KD (Wilson et al., 2017). It should be mentioned that in the study of Wilson and colleagues (2017), the final measurements were made after one week of carbohydrate reintroduction that could have modified the final results through glycogen replenishment. While caloric restriction, fasting and ketogenic diet share many mechanisms (Paoli et al., 2019), the effects of $\mathrm{KD}$ on testosterone levels seem negligible, opposite to caloric restriction (Cangemi et al., 2010) and fasting (Moro et al., 2016) that both reduce the main androgenic hormone.

The majority of studies performed on human subjects demonstrated a strong decrease in insulin levels after KD (Bueno et al., 2013; Fery et al., 1982), with the notable exception of the aforementioned Wilson et al.'s study (Wilson et al., 2017). Decreases in insulin levels are clearly related to the dramatic reduction of carbohydrate intake and it could be stated that one of the main effects of ketogenic diet relies on this reduction (Paoli et al., 2015a).

\section{Muscle's mass regulatory pathways}

Mechanisms underlying the skeletal muscle protein balance during $\mathrm{KD}$ and resistance training are still not clear. One of the more often advocated mechanism is the activation of the AMP-activated protein kinase. AMPK phosphorylation blunts Akt/mTOR pathways. But, although it has been demonstrated that fasting induces muscle AMPK activation in animals' models (Lee et al., 2017), in humans available data do not confirm these results; indeed, fasting in humans seems to reduce activation of Akt pathways without affecting AMPK (Wijngaarden et al., 2014). Regarding the effects of KD on these pathways, Kennedy and colleagues (2007) demonstrated a threefold increase in AMPK activity in the soleus muscle of rats fed with $\mathrm{KD}$, but no relevant data are available in humans.

Indeed, little data are available about how KD influences skeletal muscle's mass regulatory pathways, and most of them are only available in animal models. Roberts and colleagues (2016) demonstrated that in rats a LCKD induced only mild ketosis. In that study, LCKD did not affect basal muscular signalling and moreover, it did not affect acute muscle response to exercise measured with MPS. Furthermore, in that study, even during chronic resistance exercise, LCKD did not impair glycogen, total RNA, myofibril protein levels, or mRNA expression patterns in skeletal muscle. Again, in a further study of the same authors, it was demonstrated that 1 month of $\mathrm{KD}$ was able to improve the preservation of the relative mass of gastrocnemius and other hind limb muscles in aging mice. Interestingly, mice that subjected to KD did not show the age-related decrease in grip strength compared to control mice, suggesting that ketogenic diet may improve and preserve forelimb grip strength during aging (Roberts et al., 2017). It has been shown that in mice skeletal muscle, KD induced an increase in p-4E-BP1 (downstream of mTOR) levels with no changes in phosphorylated AMPK, p-Akt or pErk1/2 compared to control. Those authors suggested that their results might be linked to higher protein intake compared to other $\mathrm{KD}$ in animal models (Roberts et al., 2016; Roberts et al., 2017). Another target of metabolic changes 
induced by KD is Akt. Akt is involved in different cellular processes such as cell growth, proliferation, apoptosis, transcription, angiogenesis, migration, and glucose metabolism and it is also activated following a great number of stimuli among which insulin and insulin-like growth factor are of greatest importance (Sandri et al., 2013). In turn, Akt acts on target proteins that include glycogen synthase kinase 3, mammalian target of rapamycin (mTOR), p70S6K, PHAS-1 (4EBP-1), and Foxo family (Sharples et al., 2015). Akt shows three isoforms, Akt1, Akt2 and Akt3; the first isoform regulates the cell growth process and recent research indicates that it is a potential target to treat obesity because of its role in energy metabolism (Matheny et al., 2018). In this regard, BHB inhibits directly AKT (Yamada et al., 2010) and this mechanism may be responsible for the temporary KD-induced insulin resistance found in different tissues such as muscle and heart that preserves glucose for brain's use (Grandl et al., 2018; Rojas-Morales et al., 2016). On the other hand, this inhibition may negatively affect muscle mass.

\section{Ketogenic diet and skeletal muscle glycogen}

One important component of muscle mass is glycogen. Glycogen is stored in skeletal muscles at a rate of $500 \mathrm{~g}$ (Murray and Rosenbloom, 2018) and each gram of glycogen is bound to 3 grams of water (Fernandez-Elias et al., 2015), thus glycogen and associated water may significantly contribute to the whole muscle mass in athletes, especially in activities such as competitive body building (Robinson et al., 2015; Schoenfeld, 2010). Despite intuitive reasoning: no carbohydrate from food $=$ less glycogen storage, research has indicated that during endurance exercise, nutritional ketosis alters substrate competition and reduces glycolysis, promoting the preservation of glycogen resources to enhance muscle performance (Cox et al., 2016). More generally, ketosis related to both chronic high-fat, lowcarbohydrate diet, or KE intake, decreases glycogen breakdown at rest as well as during exercise (Cox et al., 2016; Vandoorne et al., 2017; Volek et al., 2016; Webster et al., 2016).

\section{Histone acetylation mechanisms}

Histone acetylation plays numerous roles in muscle control and different classes of histone deactylase have different effects on skeletal muscle such as control of contracting proteins, calcium channels and, in general, muscle health. BHB mediates inhibition of histone deacetylase (HDAC) activity in vivo (Roberts et al., 2017). HDAC inhibitors increased the lifespan by a still not very well known mechanism, yet associated with hyperacetylation of histones and a large number of other proteins (Roberts et al., 2016). Moreover, KD inhibits HDAC activity modifying related gene transcription and leads to reduced oxidative damage that could help the maintenance of muscle mass (Wang et al., 2017). Also acetoacetate may play an important role as a signalling molecule in muscle cells and there is some evidence suggesting that this ketone body can improve muscular dystrophy and accelerate muscle regeneration (Zou et al., 2016). However, more studies need to address the potential function of these two KBs on the acetylation process.

\section{Conclusions}

Nutrients, growth factors, hormones, and muscle activity generate cellular signals that have the capacity to maintain and/or grow muscle mass. The regulation of skeletal muscle mass, in fact, reflects changes in protein synthesis and protein degradation, and several stimuli lead to protein synthesis and subsequent muscle hypertrophy. Indeed, nutrition is a key factor for muscle mass balance and macronutrients' distribution, and the quantity may influence muscle growth and muscle response to training. The question that should be addressed is whether a diet in which one of the macronutrients is restricted, i.e. carbohydrates in KD, may affect skeletal muscle hypertrophy.

KD theoretically may affect skeletal muscle mass control pathways in several ways (Figure 2), but data provided by scientific literature suggest a negligible or no effect of KD on muscle mass with concomitant resistance training. KD may instead exert a protective effect against muscle mass loss during aging or during low calorie diets. The total effect seems to consist in the maintenance of muscle mass rather than a net hypertrophic effect. 


\section{References}

Ari C, Poff AM, Held HE, Landon CS, Goldhagen CR, Mavromates N, D'Agostino DP. Metabolic therapy with Deanna Protocol supplementation delays disease progression and extends survival in amyotrophic lateral sclerosis (ALS) mouse model. PLoS One, 2014; 9: e103526

Atherton PJ, Greenhaff PL, Phillips SM, Bodine SC, Adams CM, Lang CH. Control of skeletal muscle atrophy in response to disuse: clinical/preclinical contentions and fallacies of evidence. Am J Physiol Endocrinol Metab, 2016; 311: E594-604

Avruch J, Hara K, Lin Y, Liu M, Long X, Ortiz-Vega S, Yonezawa K. Insulin and amino-acid regulation of mTOR signaling and kinase activity through the Rheb GTPase. Oncogene, 2006; 25: 6361-6372

Bar-Peled L, Sabatini DM. SnapShot: mTORC1 signaling at the lysosomal surface. Cell, 2012; 151: 13901390.e1391

Biolo G, Gastaldelli A, Zhang XJ, Wolfe RR. Protein synthesis and breakdown in skin and muscle: a leg model of amino acid kinetics. Am J Physiol, 1994; 267: E467-474

Biolo G, Fleming RY, Maggi SP, Wolfe RR. Transmembrane transport and intracellular kinetics of amino acids in human skeletal muscle. Am J Physiol, 1995; 268: E75-84

Bodine SC, Baehr LM. Skeletal muscle atrophy and the E3 ubiquitin ligases MuRF1 and MAFbx/atrogin-1. Am J Physiol Endocrinol Metab, 2014; 307: E469-484

Bodine SC, Stitt TN, Gonzalez M, Kline WO, Stover GL, Bauerlein R, Zlotchenko E, Scrimgeour A, Lawrence JC, Glass DJ, Yancopoulos GD. Akt/mTOR pathway is a crucial regulator of skeletal muscle hypertrophy and can prevent muscle atrophy in vivo. Nat Cell Biol, 2001; 3: 1014-1019

Boison D. New insights into the mechanisms of the ketogenic diet. Curr Opin Neurol, 2017; 30: 187-192

Bortz WM, Paul P, Haff AC, Holmes WL. Glycerol turnover and oxidation in man. J Clin Invest, 1972; 51: 1537-1546

Bough K. Energy metabolism as part of the anticonvulsant mechanism of the ketogenic diet. Epilepsia, 2008; 49 Suppl 8: 91-93

Bough KJ, Rho JM. Anticonvulsant mechanisms of the ketogenic diet. Epilepsia, 2007; 48: 43-58

Brunet A, Bonni A, Zigmond MJ, Lin MZ, Juo P, Hu LS, Anderson MJ, Arden KC, Blenis J, Greenberg ME. Akt promotes cell survival by phosphorylating and inhibiting a Forkhead transcription factor. Cell, 1999; 96: 857-868

Bueno NB, de Melo IS, de Oliveira SL, da Rocha Ataide T. Very-low-carbohydrate ketogenic diet v. low-fat diet for long-term weight loss: a meta-analysis of randomised controlled trials. Br J Nutr, 2013; 110: 1178-1187

Cangemi R, Friedmann AJ, Holloszy JO, Fontana L. Long-term effects of calorie restriction on serum sexhormone concentrations in men. Aging Cell, 2010; 9: 236-242

Cheng SW, Fryer LG, Carling D, Shepherd PR. Thr2446 is a novel mammalian target of rapamycin (mTOR) phosphorylation site regulated by nutrient status. J Biol Chem, 2004; 279: 15719-15722

Churchward-Venne TA, Holwerda AM, Phillips SM, van Loon LJ. What is the Optimal Amount of Protein to Support Post-Exercise Skeletal Muscle Reconditioning in the Older Adult? Sports Med, 2016; 46: 12051212

Cox PJ, Kirk T, Ashmore T, Willerton K, Evans R, Smith A, Murray AJ, Stubbs B, West J, McLure SW, King MT, Dodd MS, Holloway C, Neubauer S, Drawer S, Veech RL, Griffin JL, Clarke K. Nutritional Ketosis Alters Fuel Preference and Thereby Endurance Performance in Athletes. Cell Metab, 2016; 24: 256-268

Dargelos E, Poussard S, Brulé C, Daury L, Cottin P. Calcium-dependent proteolytic system and muscle dysfunctions: a possible role of calpains in sarcopenia. Biochimie, 2008; 90: 359-368

Di Lorenzo C, Coppola G, Di Lenola D, Evangelista M, Sirianni G, Rossi P, Di Lorenzo G, Serrao M, Pierelli F. Efficacy of Modified Atkins Ketogenic Diet in Chronic Cluster Headache: An Open-Label, SingleArm, Clinical Trial. Front Neurol, 2018; 9: 64

Dickinson JM, Fry CS, Drummond MJ, Gundermann DM, Walker DK, Glynn EL, Timmerman KL, Dhanani S, Volpi E, Rasmussen BB. Mammalian target of rapamycin complex 1 activation is required for the 
stimulation of human skeletal muscle protein synthesis by essential amino acids. J Nutr, 2011; 141: 856862

Dreyer HC, Fujita S, Cadenas JG, Chinkes DL, Volpi E, Rasmussen BB. Resistance exercise increases AMPK activity and reduces 4E-BP1 phosphorylation and protein synthesis in human skeletal muscle. $J$ Physiol, 2006; 576: 613-624

Drummond MJ, Fry CS, Glynn EL, Dreyer HC, Dhanani S, Timmerman KL, Volpi E, Rasmussen BB. Rapamycin administration in humans blocks the contraction-induced increase in skeletal muscle protein synthesis. J Physiol, 2009; 587: 1535-1546

Egan B, Zierath JR. Exercise metabolism and the molecular regulation of skeletal muscle adaptation. Cell Metab, 2013; 17: 162-184

Escobar KA, VanDusseldorp TA, Kerksick CM. Carbohydrate intake and resistance-based exercise: are current recommendations reflective of actual need? Br J Nutr, 2016; 116: 2053-2065

Fernandez-Elias VE, Ortega JF, Nelson RK, Mora-Rodriguez R. Relationship between muscle water and glycogen recovery after prolonged exercise in the heat in humans. Eur J Appl Physiol, 2015; 115: 19191926

Fery F, Bourdoux P, Christophe J, Balasse EO. Hormonal and metabolic changes induced by an isocaloric isoproteinic ketogenic diet in healthy subjects. Diabete Metab, 1982; 8: 299-305

Figueiredo VC, Markworth JF, Cameron-Smith D. Considerations on mTOR regulation at serine 2448: implications for muscle metabolism studies. Cell Mol Life Sci, 2017; 74: 2537-2545

Fry CS, Drummond MJ, Glynn EL, Dickinson JM, Gundermann DM, Timmerman KL, Walker DK, Volpi E, Rasmussen BB. Skeletal muscle autophagy and protein breakdown following resistance exercise are similar in younger and older adults. J Gerontol A Biol Sci Med Sci, 2013; 68: 599-607

Fukao T, Lopaschuk GD, Mitchell GA. Pathways and control of ketone body metabolism: on the fringe of lipid biochemistry. Prostaglandins Leukot Essent Fatty Acids, 2004; 70: 243-251

Garcia D, Shaw RJ. AMPK: Mechanisms of Cellular Energy Sensing and Restoration of Metabolic Balance. Mol Cell, 2017; 66: 789-800

Glass DJ. Signalling pathways that mediate skeletal muscle hypertrophy and atrophy. Nat Cell Biol, 2003; 5: $87-90$

Goll DE, Thompson VF, Taylor RG, Christiansen JA. Role of the calpain system in muscle growth. Biochimie, 1992; 74: 225-237

Gordon SE, Lake JA, Westerkamp CM, Thomson DM. Does AMP-activated protein kinase negatively mediate aged fast-twitch skeletal muscle mass? Exerc Sport Sci Rev, 2008; 36: 179-186

Grandl G, Straub L, Rudigier C, Arnold M, Wueest S, Konrad D, Wolfrum C. Short-term feeding of a ketogenic diet induces more severe hepatic insulin resistance than an obesogenic high-fat diet. $J$ Physiol, 2018; 596: 4597-4609

Greene DA, Varley BJ, Hartwig TB, Chapman P, Rigney M. A Low-Carbohydrate Ketogenic Diet Reduces Body Mass Without Compromising Performance in Powerlifting and Olympic Weightlifting Athletes. J Strength Cond Res, 2018; 32: 3373-3382

Gwinn DM, Shackelford DB, Egan DF, Mihaylova MM, Mery A, Vasquez DS, Turk BE, Shaw RJ. AMPK phosphorylation of raptor mediates a metabolic checkpoint. Mol Cell, 2008; 30: 214-226

Hector AJ, McGlory C, Damas F, Mazara N, Baker SK, Phillips SM. Pronounced energy restriction with elevated protein intake results in no change in proteolysis and reductions in skeletal muscle protein synthesis that are mitigated by resistance exercise. FASEB J, 2018; 32: 265-275

Holz MK, Ballif BA, Gygi SP, Blenis J. mTOR and S6K1 mediate assembly of the translation preinitiation complex through dynamic protein interchange and ordered phosphorylation events. Cell, 2005; 123: 569-580

Hoppeler H, Baum O, Lurman G, Mueller M. Molecular mechanisms of muscle plasticity with exercise. Compr Physiol, 2011; 1: 1383-1412

Horman S, Browne G, Krause U, Patel J, Vertommen D, Bertrand L, Lavoinne A, Hue L, Proud C, Rider M. Activation of AMP-activated protein kinase leads to the phosphorylation of elongation factor 2 and an inhibition of protein synthesis. Curr Biol, 2002; 12: 1419-1423 
Jabekk PT, Moe IA, Meen HD, Tomten SE, Hostmark AT. Resistance training in overweight women on a ketogenic diet conserved lean body mass while reducing body fat. Nutr Metab (Lond), 2010; 7: 17

Kennedy AR, Pissios P, Otu H, Roberson R, Xue B, Asakura K, Furukawa N, Marino FE, Liu FF, Kahn BB, Libermann TA, Maratos-Flier E. A high-fat, ketogenic diet induces a unique metabolic state in mice. American journal of physiology. Endocrinology and metabolism, 2007; 292: E1724-1739

Kephart WC, Pledge CD, Roberson PA, Mumford PW, Romero MA, Mobley CB, Martin JS, Young KC, Lowery RP, Wilson JM, Huggins KW, Roberts MD. The Three-Month Effects of a Ketogenic Diet on Body Composition, Blood Parameters, and Performance Metrics in CrossFit Trainees: A Pilot Study. Sports (Basel), 2018; 6

Klement RJ. The emerging role of ketogenic diets in cancer treatment. Curr Opin Clin Nutr Metab Care, 2019; 22: 129-134

Krebs HA. The regulation of the release of ketone bodies by the liver. Adv Enzyme Regul, 1966; 4: 339-354

Lee D, Martinez B, Crocker DE, Ortiz RM. Fasting increases the phosphorylation of AMPK and expression of sirtuin1 in muscle of adult male northern elephant seals (Mirounga angustirostris). Physiol Rep, 2017; 5

Long X, Lin Y, Ortiz-Vega S, Yonezawa K, Avruch J. Rheb binds and regulates the mTOR kinase. Curr Biol, 2005; 15: 702-713

Macnaughton LS, Wardle SL, Witard OC, McGlory C, Hamilton DL, Jeromson S, Lawrence CE, Wallis GA, Tipton KD. The response of muscle protein synthesis following whole-body resistance exercise is greater following $40 \mathrm{~g}$ than $20 \mathrm{~g}$ of ingested whey protein. Physiol Rep, 2016; 4

Masiero E, Agatea L, Mammucari C, Blaauw B, Loro E, Komatsu M, Metzger D, Reggiani C, Schiaffino S, Sandri M. Autophagy is required to maintain muscle mass. Cell Metab, 2009; 10: 507-515

Matheny RW, Jr., Geddis AV, Abdalla MN, Leandry LA, Ford M, McClung HL, Pasiakos SM. KT2 is the predominant AKT isoform expressed in human skeletal muscle. Physiol Rep, 2018; 6: e13652

Mavropoulos JC, Yancy WS, Hepburn J, Westman EC. The effects of a low-carbohydrate, ketogenic diet on the polycystic ovary syndrome: a pilot study. Nutr Metab (Lond), 2005; 2: 35

McPherson PA, McEneny J. The biochemistry of ketogenesis and its role in weight management, neurological disease and oxidative stress. J Physiol Biochem, 2012; 68: 141-151

Merrill GF, Kurth EJ, Hardie DG, Winder WW. AICA riboside increases AMP-activated protein kinase, fatty acid oxidation, and glucose uptake in rat muscle. Am J Physiol, 1997; 273: E1107-1112

Mitchell WK, Wilkinson DJ, Phillips BE, Lund JN, Smith K, Atherton PJ. Human Skeletal Muscle Protein Metabolism Responses to Amino Acid Nutrition. Adv Nutr, 2016; 7: 828S-838S

Moore DR, Robinson MJ, Fry JL, Tang JE, Glover EI, Wilkinson SB, Prior T, Tarnopolsky MA, Phillips SM. Ingested protein dose response of muscle and albumin protein synthesis after resistance exercise in young men. The American Journal of Clinical Nutrition, 2009; 89: 161-168

Moro T, Tinsley G, Bianco A, Marcolin G, Pacelli QF, Battaglia G, Palma A, Gentil P, Neri M, Paoli A. Effects of eight weeks of time-restricted feeding (16/8) on basal metabolism, maximal strength, body composition, inflammation, and cardiovascular risk factors in resistance-trained males. J Transl Med, 2016; $14: 290$

Morton RW, McGlory C, Phillips SM. Nutritional interventions to augment resistance training-induced skeletal muscle hypertrophy. Front Physiol, 2015; 6: 245

Mounier R, Théret M, Lantier L, Foretz M, Viollet B. Expanding roles for AMPK in skeletal muscle plasticity. Trends Endocrinol Metab, 2015; 26: 275-286

Murray B, Rosenbloom C. Fundamentals of glycogen metabolism for coaches and athletes. Nutr Rev, 2018; 76: 243-259

Murton AJ, Constantin D, Greenhaff PL. The involvement of the ubiquitin proteasome system in human skeletal muscle remodelling and atrophy. Biochim Biophys Acta, 2008; 1782: 730-743

Newman JC, Verdin E. Ketone bodies as signaling metabolites. Trends Endocrinol Metab, 2014; 25(1): 42-52

Olson CA, Vuong HE, Yano JM, Liang QY, Nusbaum DJ, Hsiao EY. The Gut Microbiota Mediates the AntiSeizure Effects of the Ketogenic Diet. Cell; 2018, 174: 497

Ota M, Matsuo J, Ishida I, Takano H, Yokoi Y, Hori H, Yoshida S, Ashida K, Nakamura K, Takahashi T, Kunugi $\mathrm{H}$. Effects of a medium-chain triglyceride-based ketogenic formula on cognitive function in 
patients with mild-to-moderate Alzheimer's disease. Neurosci Lett, 2019; 690: 232-236

Pacy PJ, Cheng KN, Thompson GN, Halliday D. Stable isotopes as tracers in clinical research. Ann Nutr Metab, 1989; 33: 65-78

Paddon-Jones D, Short KR, Campbell WW, Volpi E, Wolfe RR. Role of dietary protein in the sarcopenia of aging. Am J Clin Nutr, 2008; 87: 1562S-1566S

Paoli A. Ketogenic diet for obesity: friend or foe? Int J Environ Res Public Health, 2014; 11: 2092-2107

Paoli A. Booster Ketones: Battling Hunger. Obesity (Silver Spring), 2018; 26: 252-253

Paoli A, Bianco A, Grimaldi KA. The Ketogenic Diet and Sport: A Possible Marriage? Exerc Sport Sci Rev, 2015a; 43: 153-162

Paoli A, Rubini A, Volek JS, Grimaldi KA. Beyond weight loss: a review of the therapeutic uses of very-lowcarbohydrate (ketogenic) diets. Eur J Clin Nutr, 2013; 67: 789-796

Paoli A, Bianco A, Damiani E, Bosco G. Ketogenic Diet in Neuromuscular and Neurodegenerative Diseases. Biomed Res Int, 2014; 2014: 474296

Paoli A, Tinsley G, Bianco A, Moro T. The Influence of Meal Frequency and Timing on Health in Humans: The Role of Fasting. Nutrients, 2019; 11

Paoli A, Grimaldi K, D'Agostino D, Cenci L, Moro T, Bianco A, Palma A. Ketogenic diet does not affect strength performance in elite artistic gymnasts. J Int Soc Sports Nutr, 2012; 9: 34

Paoli A, Moro T, Bosco G, Bianco A, Grimaldi KA, Camporesi E, Mangar D. Effects of n-3 polyunsaturated fatty acids (omega-3) supplementation on some cardiovascular risk factors with a ketogenic Mediterranean diet. Mar Drugs, 2015b; 13: 996-1009

Pasiakos SM, Carbone JW. Assessment of skeletal muscle proteolysis and the regulatory response to nutrition and exercise. IUBMB Life, 2014; 66: 478-484

Phillips SM. The science of muscle hypertrophy: making dietary protein count. Proc Nutr Soc, 2011; 70: 100103

Phillips SM. Dietary protein requirements and adaptive advantages in athletes. Br J Nutr, 2012; 108 Suppl 2: S158-167

Phillips SM. Current Concepts and Unresolved Questions in Dietary Protein Requirements and Supplements in Adults. Front Nutr, 2017; 4: 13

Reidy PT, Rasmussen BB. Role of Ingested Amino Acids and Protein in the Promotion of Resistance ExerciseInduced Muscle Protein Anabolism. J Nutr, 2016; 146: 155-183

Rho JM. How does the ketogenic diet induce anti-seizure effects? Neurosci Lett, 2017; 637: 4-10

Roberts MD, Holland AM, Kephart WC, Mobley CB, Mumford PW, Lowery RP, Fox CD, McCloskey AE, Shake JJ, Mesquita P, Patel RK, Martin JS, Young KC, Kavazis AN, Wilson JM. A putative lowcarbohydrate ketogenic diet elicits mild nutritional ketosis but does not impair the acute or chronic hypertrophic responses to resistance exercise in rodents. J Appl Physiol (1985), 2016; 120: 1173-1185

Roberts MN, Wallace MA, Tomilov AA, Zhou Z, Marcotte GR, Tran D, Perez G, Gutierrez-Casado E, Koike S, Knotts TA, Imai DM, Griffey SM, Kim K, Hagopian K, McMackin MZ, Haj FG, Baar K, Cortopassi GA, Ramsey JJ, Lopez-Dominguez JA. A Ketogenic Diet Extends Longevity and Healthspan in Adult Mice. Cell Metab, 2017; 26: 539-546 e535

Robinson SL, Lambeth-Mansell A, Gillibrand G, Smith-Ryan A, Bannock L. A nutrition and conditioning intervention for natural bodybuilding contest preparation: case study. J Int Soc Sports Nutr, 2015; 12: 20

Rojas-Morales P, Tapia E, Pedraza-Chaverri J. beta-Hydroxybutyrate: A signaling metabolite in starvation response? Cell Signal, 2016; 28: 917-923

Romanello V, Guadagnin E, Gomes L, Roder I, Sandri C, Petersen Y, Milan G, Masiero E, Del Piccolo P, Foretz M, Scorrano L, Rudolf R, Sandri M. Mitochondrial fission and remodelling contributes to muscle atrophy. EMBO J, 2010; 29: 1774-1785

Rose AJ, Richter EA. Regulatory mechanisms of skeletal muscle protein turnover during exercise. J Appl Physiol (1985), 2009; 106: 1702-1711

Ruan HB, Crawford PA. Ketone bodies as epigenetic modifiers. Curr Opin Clin Nutr Metab Care, 2018; 21: 260-266 
Sandri M, Barberi L, Bijlsma AY, Blaauw B, Dyar KA, Milan G, Mammucari C, Meskers CGM, Pallafacchina G, Paoli A, Pion D, Roceri M, Romanello V, Serrano AL, Toniolo L, Larsson L, Maier AB, MunozCanoves P, Musaro A, Pende M, Reggiani C, Rizzuto R, Schiaffino S. Signalling pathways regulating muscle mass in ageing skeletal muscle. The role of the IGF1-Akt-mTOR-FoxO pathway. Biogerontology, 2013; 14: 303-323

Saxton RA, Sabatini DM. mTOR Signaling in Growth, Metabolism, and Disease. Cell, 2017; 169: 361-371

Schiaffino S, Mammucari C. Regulation of skeletal muscle growth by the IGF1-Akt/PKB pathway: insights from genetic models. Skeletal muscle, 2011; 1: 4

Schoenfeld BJ. The mechanisms of muscle hypertrophy and their application to resistance training. J Strength Cond Res, 2010; 24: 2857-2872

Sharples AP, Hughes DC, Deane CS, Saini A, Selman C, Stewart CE. Longevity and skeletal muscle mass: the role of IGF signalling, the sirtuins, dietary restriction and protein intake. Aging Cell, 2015; 14: 511-523

Stokes T, Hector AJ, Morton RW, McGlory C, Phillips SM. Recent Perspectives Regarding the Role of Dietary Protein for the Promotion of Muscle Hypertrophy with Resistance Exercise Training. Nutrients, 2018; 10

Taylor MK, Sullivan DK, Mahnken JD, Burns JM, Swerdlow RH. Feasibility and efficacy data from a ketogenic diet intervention in Alzheimer's disease. Alzheimers Dement (NY), 2018; 4: 28-36

Thompson GN, Pacy PJ, Ford GC, Halliday D. Practical considerations in the use of stable isotope labelled compounds as tracers in clinical studies. Biomed Environ Mass Spectrom, 1989; 18: 321-327

Thomson DM, Gordon SE. Diminished overload-induced hypertrophy in aged fast-twitch skeletal muscle is associated with AMPK hyperphosphorylation. J Appl Physiol (1985), 2005; 98: 557-564

Thomson DM, Fick CA, Gordon SE. AMPK activation attenuates S6K1, 4E-BP1, and eEF2 signaling responses to high-frequency electrically stimulated skeletal muscle contractions. J Appl Physiol (1985), 2008; 104: 625-632

Thoreen CC, Chantranupong L, Keys HR, Wang T, Gray NS, Sabatini DM. A unifying model for mTORC1mediated regulation of mRNA translation. Nature, 2012; 485: 109-113

Tipton KD, Phillips SM. Dietary protein for muscle hypertrophy. Nestle Nutr Inst Workshop Ser, 2013; 76: 7384

van Loon LJ, Gibala MJ. Dietary protein to support muscle hypertrophy. Nestle Nutr Inst Workshop Ser, 2011; 69: 79-89; discussion 89-95

Vandoorne T, De Smet S, Ramaekers M, Van Thienen R, De Bock K, Clarke K, Hespel P. Intake of a Ketone Ester Drink during Recovery from Exercise Promotes mTORC1 Signaling but Not Glycogen Resynthesis in Human Muscle. Front Physiol, 2017; 8: 310

Vargas S, Romance R, Petro JL, Bonilla DA, Galancho I, Espinar S, Kreider RB, Benitez-Porres J. Efficacy of ketogenic diet on body composition during resistance training in trained men: a randomized controlled trial. J Int Soc Sports Nutr, 2018; 15: 31

Veech RL. The therapeutic implications of ketone bodies: the effects of ketone bodies in pathological conditions: ketosis, ketogenic diet, redox states, insulin resistance, and mitochondrial metabolism. Prostaglandins Leukot Essent Fatty Acids, 2004; 70: 309-319

Volek JS, Gomez AL, Love DM, Avery NG, Sharman MJ, Kraemer WJ. Effects of a high-fat diet on postabsorptive and postprandial testosterone responses to a fat-rich meal. Metabolism, 2001; 50: 13511355

Volek JS, Freidenreich DJ, Saenz C, Kunces LJ, Creighton BC, Bartley JM, Davitt PM, Munoz CX, Anderson JM, Maresh CM, Lee EC, Schuenke MD, Aerni G, Kraemer WJ, Phinney SD. Metabolic characteristics of keto-adapted ultra-endurance runners. Metabolism, 2016; 65: 100-110

Wackerhage H, Schoenfeld BJ, Hamilton DL, Lehti M, Hulmi JJ. Stimuli and sensors that initiate skeletal muscle hypertrophy following resistance exercise. J Appl Physiol (1985), 2019; 126: 30-43

Wang L, Rhodes CJ, Lawrence JC. Activation of mammalian target of rapamycin (mTOR) by insulin is associated with stimulation of 4EBP1 binding to dimeric mTOR complex 1. J Biol Chem, 2006; 281: 24293-24303 
Wang X, Wu X, Liu Q, Kong G, Zhou J, Jiang J, Wu X, Huang Z, Su W, Zhu Q. Ketogenic Metabolism Inhibits Histone Deacetylase (HDAC) and Reduces Oxidative Stress After Spinal Cord Injury in Rats. Neuroscience, 2017; 366: 36-43

Webster CC, Noakes TD, Chacko SK, Swart J, Kohn TA, Smith JA. Gluconeogenesis during endurance exercise in cyclists habituated to a long-term low carbohydrate high-fat diet. J Physiol, 2016; 594: 43894405

Weerasekara VK, Panek DJ, Broadbent DG, Mortenson JB, Mathis AD, Logan GN, Prince JT, Thomson DM, Thompson JW, Andersen JL. Metabolic-stress-induced rearrangement of the 14-3-3 $\zeta$ interactome promotes autophagy via a ULK1- and AMPK-regulated 14-3-3 $\zeta$ interaction with phosphorylated Atg9. Mol Cell Biol, 2014; 34: 4379-4388

Wijngaarden MA, Bakker LE, van der Zon GC, t Hoen PA, van Dijk KW, Jazet IM, Pijl H, Guigas B. Regulation of skeletal muscle energy/nutrient-sensing pathways during metabolic adaptation to fasting in healthy humans. Am J Physiol Endocrinol Metab, 2014; 307: E885-895

Wilson JM, Lowery RP, Roberts MD, Sharp MH, Joy JM, Shields KA, Partl J, Volek JS, D'Agostino D. The Effects of Ketogenic Dieting on Body Composition, Strength, Power, and Hormonal Profiles in Resistance Training Males. J Strength Cond Res, 2017

Winder WW, Thomson DM. Cellular energy sensing and signaling by AMP-activated protein kinase. Cell Biochem Biophys, 2007; 47: 332-347

Witard OC, Wardle SL, Macnaughton LS, Hodgson AB, Tipton KD. Protein Considerations for Optimising Skeletal Muscle Mass in Healthy Young and Older Adults. Nutrients, 2016; 8: 181

Wolfe RR. Branched-chain amino acids and muscle protein synthesis in humans: myth or reality? J Int Soc Sports Nutr, 2017; 14: 30

Wolfe RR, Chinkes DL. Isotope tracers in metabolic research : principles and practice of kinetic analysis. Wiley-Liss, Hoboken, N.J.; 2005

Wood RJ, Gregory SM, Sawyer J, Milch CM, Matthews TD, Headley SA. Preservation of fat-free mass after two distinct weight loss diets with and without progressive resistance exercise. Metab Syndr Relat Disord, 2012; 10: 167-174

Yamada T, Zhang SJ, Westerblad H, Katz A. \{beta\}-Hydroxybutyrate inhibits insulin-mediated glucose transport in mouse oxidative muscle. Am J Physiol Endocrinol Metab, 2010; 299: E364-373

Zhang F, Wu H, Jin Y, Zhang X. Proton Magnetic Resonance Spectroscopy (H1-MRS) Study of the Ketogenic Diet on Repetitive Mild Traumatic Brain Injury in Adolescent Rats and Its Effect on Neurodegeneration. World Neurosurg, 2018; 120: e1193-e1202

Zoncu R, Efeyan A, Sabatini DM. mTOR: from growth signal integration to cancer, diabetes and ageing. Nat Rev Mol Cell Biol, 2011; 12: 21-35

Zou X, Meng J, Li L, Han W, Li C, Zhong R, Miao X, Cai J, Zhang Y, Zhu D. Acetoacetate Accelerates Muscle Regeneration and Ameliorates Muscular Dystrophy in Mice. J Biol Chem, 2016; 291: 2181-2195

\section{Corresponding author:}

\section{Prof. Antonio Paoli.}

Department of Biomedical Sciences, University of Padua, Padua, Italy and Research Center for High Performance Sport, UCAM, Catholic University of Murcia, Murcia 30107, Spain.

Phone: 00390498275318

Fax: 00390498275301

E-mail: antonio.paoli@unipd.it 